\title{
Evaluation of Free Vascularized Groin Lymph Nodes Transfer for Treatment of Secondary Upper Limb Lymphedema
}

\author{
Usama Abdelfattah ${ }^{1, *}$ MD., Fawzy Hamza ${ }^{1}$ MD., Wael Ayad ${ }^{1}$ MD., Tarek Elbanoby ${ }^{1}$ MD. \\ and Joon Pio Hong ${ }^{2}$ MD.
}

\section{* Corresponding Author: \\ Usama Abdelfattah \\ Usamaabdelfattah@hotmail.com}

Received for publication April 25, 2020; Accepted June 04, 2021; Published online June 04, 2021.

Copyright The Authors published by Al-Azhar University, Faculty of Medicine, Cairo, Egypt. Users have the right to read, download, copy, distribute, print, search, or link to the full texts of articles under the following conditions: Creative Commons Attribution-Share Alike 4.0 International Public License (CC BY-SA 4.0).

doi: $10.21608 /$ aimj.2021.73401.1461

${ }^{1}$ Department of Plastic and Reconstructive Surgery, Al-Azhar University, Cairo, Egypt.

${ }^{2}$ Department of Plastic and Reconstructive Surgery, Asan Medical Center, Ulsan university, Seoul-South Korea.

\begin{abstract}
Background: Vascularized lymph node flap transfer is a recent approach used for the treatment of breast cancer-related upper limb lymphedema. Aim of the work: To evaluate the effect of vascularized lymph node transfer in the management of secondary upper extremity lymphedema.

Patients and Methods: A prospective randomized clinical study was conducted including 30 patients stage II-III breast cancer-related lymphedema (BCRL) between December 2017 till June 2020. 15 patients underwent vascularized groin lymph node flap transfer (group B) using the axilla $(\mathrm{n}=7)$ or distal placement (elbow/wrist) $(\mathrm{n}=8)$ as a recipient site. 15 patients who were selected to undergo conservative therapy were used as controls. Intraoperatively, reverse lymphatic mapping using radioisotope or indocyanine green lymphography was performed to avoid iatrogenic lower extremity lymphatic injury. Outcomes were assessed using change of circumferential differentiation, volume reduction rate, and the change in episodes of cellulitis, pain, heaviness, and limb function.

Results: At a mean follow-up of $30.07 \pm 2.6$ months, the mean improvement of circumferential differentiation of group B (VGLNT) was statistically greater than that of group A (conservative physical therapy) $(8.3 \pm 2.7$ percent versus $2.1 \pm 4.6$; $\mathrm{P}<0.01)$. The evaluation of each treatment showed a significant reduction of infection rate in group $\mathrm{B}$ compared with group A ( $<<0.001)$.

Conclusion: Vascularized groin lymph node flap transfer using the axilla or distal forearm as a recipient site is an effective and reliable approach for treating breast cancer-related lymphedema.
\end{abstract}

Keywords: Lymphedema; Lymph node transfer; Breast cancer-related lymphedema (BCRL).

Disclosure: The authors have no financial interest to declare in relation to the content of this article. The Article Processing Charge was paid for by the authors.

Authorship: All authors have a substantial contribution to the article.

compliance, and average results. ${ }^{5,6}$ Surgical options, which include ablative operations, liposuction, and physiologic microsurgical operations, have also been used, with mixed results. The current microsurgical approaches including lymphatic-ovenous anastomosis (LVA) and vascularized node transfer (VLNT) had been performed to treat established lymphedema and related to the subjective improvement of lymphedema symptoms, reduced extremity volume, and enhanced quality of life. ${ }^{7-9}$ Despite advances in microsurgery, the evolution, and refinements in these microsurgical approaches, there's neither consensus on surgical or nonsurgical procedures nor a consistent protocol within the treatment of the patient with lymphedema. Given the dearth of consensus on the treatment of lymphedema, lymphedema. practitioner must have multiple surgical intervention options available.

This study aims to evaluate the effect of vascularized lymph gland transfer within the management of secondary upper extremity lymphedema.
Lymphedema could be a progressive, chronic condition that affects a major number of population health ${ }^{1-4}$ Lymphedema is particularly psychosocia surgical or radiological treatment of malignancy sufficient data, we cannot confirm the most typical causes of lymphedema in Egypt. The precise cause and pathogenesis of lymphedema continue to be not completely understood, and this has led underestimation and misdiagnosis and althoug physiological surgical intervention had been described and significantly improved the standard of unaware that treatment is on the market, or don't know where to hunt help. There are nonsurgical options, conservative treatment, also referred to as named complex decongestive therapy (CDT) that have remained unchanged for several years despite occasionally variant regimens and unstable patients,

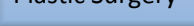




\section{PATIENTS AND METHODS}

After institutional review board approval at Al-Azhar university's ethical committee, a prospective randomized clinical study was conducted including 30 patients with breast cancer-related lymphedema (BCRL) stage II-III at Al-Azhar university hospitalsCairo and Asan Medical Center-Republic of Korea between December 2017 till June 2020. All patients were treated with vascularized groin lymphatic node transfer (VGLNT) either with or without microsurgical breast reconstruction using a Deep inferior epigastric perforator flap (DIEP).

\section{Inclusion criteria}

Patients aged 18 years or over with unilateral breast cancer-related lymphedema (BCRL) stage II or III with no signs of cellulitis at time of examination.

\section{Exclusion criteria}

(1) Non-surgical cases of upper limb lymphedema as primary conditions (lymphedema precox).

(2) Regional recurrence of the initial pathology (breast cancer).

(3) Presence of distant metastasis.

(4) Brachial plexus neuritis.

Preoperative photographic documentation and circumference measurements have executed all cases. All patients were prepared with CDT a minimum of 1 month before surgery. consent obtained from all patients before surgery.

Thirty upper extremity lymphedemas were randomly divided into two groups using simple randomization procedures:

Group A: included 15 BCRL in 15 patients treated conservatively with CDT.

Group B: Included 15 BCRL in 15 patients treated with Free Vascularized groin lymph node transfer (VGLNT).

\section{Management}

Group A: $(n=15)$ following patient education and counseling, patients were managed conservatively with the CDT regime only by a specialized lymphedema therapist for six months. The CDT included manual lymphatic massage, the appliance of multilayered short stretch bandages, skin care, and specialized exercises. Group B: $(n=15)$, underwent free vascularized groin lymph node transfer (VGLNT) followed by the identical physiotherapy regime of group A for six months.

\section{Flap design and skin marking}

The anatomical landmarks were defined and marked including the pubic tubercle (PT), anterior superior iliac spine (ASIS), Inguinal ligament, and also the inguinal crease. the central third the distance from the PT toward the ASIS and just under this line was marked because of the location of the target nodes (guided by the MRL) (Figure 1). A handheld
Doppler was then used to mark the SCIA location. A skin paddle about $5 * 10 \mathrm{~cm}$ was designed only for flap monitoring.

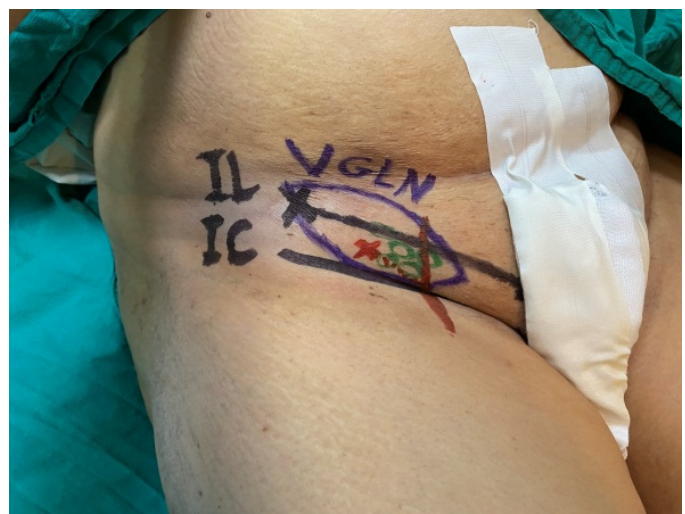

Fig. 1: Marking and design of VGLN flap

IC: Inguinal crease, IL: Inguinal Ligament, VGLN: Vascularized Groin Lymph Node

We used a two-team approach for both donor site (Flap harvesting and lymphatic mapping) and recipient site preparation in all cases of our study to minimize the surgical time.

\section{1) Free VGLN Harvest}

The patient was prepped and draped leaving the trunk exposed from the umbilicus till mid-thigh and all the upper extremity was exposed till the axilla. Usually, flap elevation started from the inferolateral side of the skin paddle design within the sub-scarpal plane. At the superior border of the flap, the superficial circumflex venous blood vessel (SCIV) and superficial inferior vena (SIEV) were dissected and isolated. The flap was then elevated lateral to medial just above the sartorius fascia with micro-clipping and bipolar cautery for the lymphatic vessels to avoid postoperative seroma and lymphorrhea. The SCIA branch to the sartorius muscle was divided, and also the vascular pedicle was dissected and to its origin at the femoral vessels and harvested for transfer (Figure 2,3).

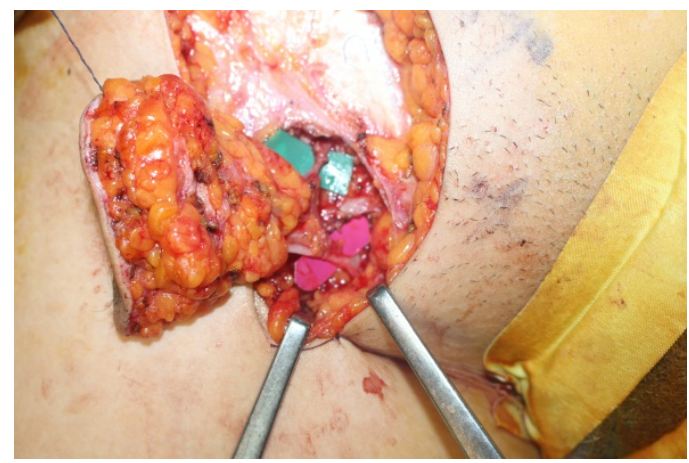

Fig. 2: VGLN Flap dissection 


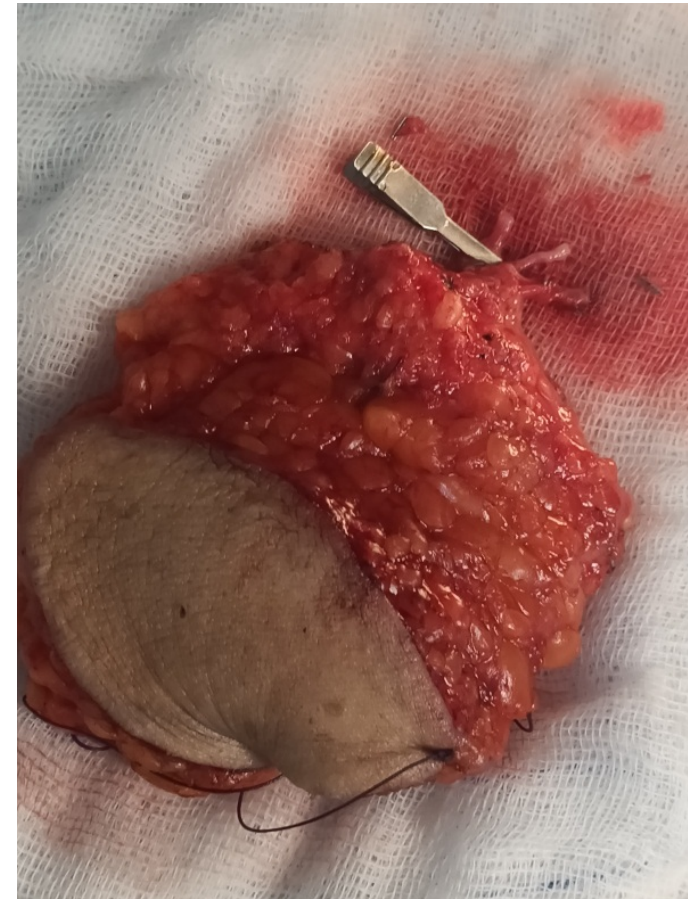

Fig. 3: Harvested VGLN flap

For patients who had postmastectomy amastia and developed BCRL, total breast reconstruction with deep inferior epigastric perforator (DIEP) flap combined with the VGLNT through block dissection was performed (Figure 4). After lymph node flap harvest, the donor site was closed layers adequately employing a quilting suture to occlude dead spaces.

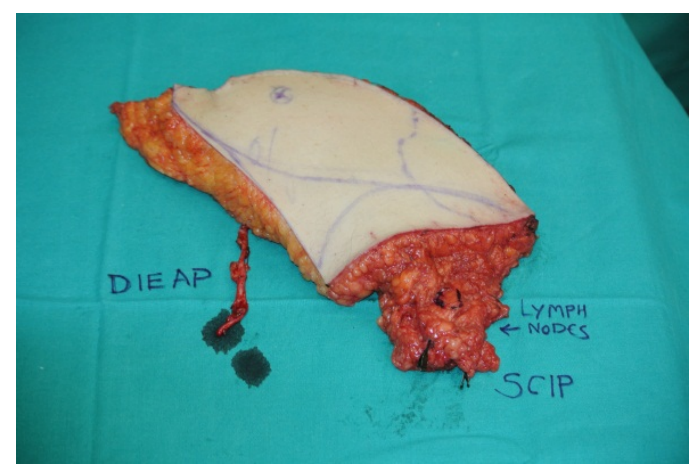

Fig. 4: Harvested combined DIEP and VGLN flaps

\section{2) Reverse lymphatic mapping (RLM)}

RLM was performed in every case of Free VGLNT as described by pons et al, to maximize the protection and avoid donor site lymphedema. ${ }^{10}$

Technetium99 (Tc99) was utilized in 4 patients while Indocyanine green (ICG) was utilized in 11 patients. Either Tc99 (0.2 mCi/0.2 ml nanocolloid, G.E Health Care S.R.L, Milano, Italy) or ICG (0.1 to $0.2 \mathrm{ml}$, of ICG $(5 \mathrm{mg} / \mathrm{ml})$ PULSION Medical Systems, Feldkirchen, Germany) was injected in subdermal plane preoperatively into the foot web spaces. Also, 0.2 to 0.4 of $2.5 \%$ Isosulfan blue $\mathrm{V}$ dye ((Bleu Patente V sodique, Guerbet 2,5\%, 2 ml, France) was injected intraoperatively into the lower abdomen above the inguinal ligament within the potential

geographical area to permit better visualization and identification of the lower abdominal superficial lymphatic vessels (Figure 5). The lymph nodes draining the lower abdomen were visualized surrounding the SCIA pedicle. The gamma probe or Infrared fluorescence was utilized to identify and preserve the sentinel node draining the lower extremity.
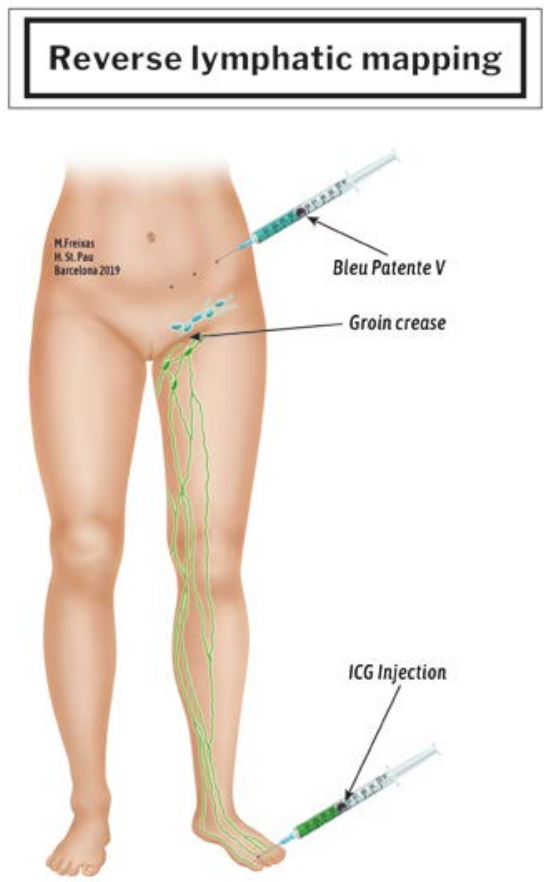

Fig. 5: Diagram Illustrating reverse lymphatic mapping

\section{Postoperative Evaluation and Follow up}

Management was delivered to both groups for six months; then follow-up for six more months, till their final evaluation.

The limb circumference was measured at $10 \mathrm{~cm}$ above and below the medial epicondyle of the elbow on both limbs preoperatively and each month postoperatively.

We also reported episodes of infection, cellulitis or lymphangitis, and subjective symptoms including functional limb activity, pain, and feeling of heaviness in a visual analog scaling system (1-10) before intervention and at 1-year follow-up.

\section{Data Management and Analysis:}

Data were presented, and suitable analysis was done in step with the sort of knowledge obtained for every parameter. Descriptive values are expressed as a variety of patients with percentages for binary variables and as mean \pm standard deviation (SD) for the continuous data if presented a traditional distribution. Those variables 
that didn't display a traditional distribution were presented as median and range.

SPSS 17.0 software (SPSS, Inc., Chicago, Ill, 2013.) was used to analyze the data. To investigate and compare the categorical variables we used the Chisquared test. Between-group comparisons were performed with the unpaired Student t-test, the Mann-Whitney U-test, or Fisher exact test, as appropriate. A p-value of $<0.05$ had considered statistically significant.

\section{RESULTS}

In this study, 30 upper extremities of 30 patients were analyzed. The 30 patients were all females and presented with unilateral BCRL. Patients were assigned randomly to either A or B each including 15 upper extremities.

\section{Patient Demographics}

We did not find statistical differences in age, BMI, smoking, diabetes, radiotherapy, chemotherapy, ISL staging or duration of symptoms between the VGLNT (B) and the physical therapy (B) groups (Table 1).

\begin{tabular}{|l|c|c|c|}
\hline & Group A & Group B & $\begin{array}{c}\boldsymbol{P} \\
\text { value }\end{array}$ \\
\hline Age (Mean) & 45.3 & 46.1 & 1.0 \\
\hline BMI (Mean) & 32.43 & 32.31 & 1.2 \\
\hline Radiotherapy & $15(100 \%)$ & $14(93.3 \%)$ & 0.6 \\
\hline
\end{tabular}

\begin{tabular}{|l|c|c|c|}
\hline Chemotherapy & $13(86.7 \%)$ & $14(93.3 \%)$ & 0.7 \\
\hline ISL Stage & $\begin{array}{c}9(60 \%) \mathrm{II} \\
6(40 \%) \mathrm{III}\end{array}$ & $\begin{array}{c}8(53.3 \%) \mathrm{II} \\
7(46.7 \%) \\
\mathrm{III}\end{array}$ & 0.6 \\
\hline DM & $1(6.7 \%)$ & $2(13.3 \%)$ & 0.12 \\
\hline Smoking & $2(13.3 \%)$ & $1(6.7 \%)$ & 0.2 \\
\hline $\begin{array}{l}\text { Duration of } \\
\text { symptoms } \\
\text { (Mean) }\end{array}$ & 37.8 & 39.6 & 0.4 \\
\hline
\end{tabular}

Table 1: Comparing group A versus B regarding demographics, co-morbidity, and clinical data.

Operative details (Group B)

All vascularized groin lymph node flaps survived. The average diameter of the SCIA was $0.9 \mathrm{~mm}$ and SCIV was $1.4 \mathrm{~mm}$. In one case, the patient developed seroma at the donor site which was managed successfully by keeping the drains inserted for 14 days and applying compression. 6 patients in the $\mathrm{B}$ group underwent DIEP flap for breast reconstruction which was combined with VGLNT and the lymph flap was placed within the axilla and anastomosed to the thoracodorsal system, while within the remaining 9 patients, 5 flaps were placed at the wrist, 3 at the elbow and 1 within the axilla (Table 2). In all cases with distal lymph node flap placement, the radial vessels and cephalic vein were the recipient's vessels. 5 patients (2 with proximal and three with distal placement) underwent de-epithelialization of the skin paddle at 1-2 years follow-up for improving the cosmetic appearance (Figure 6).

\begin{tabular}{|r|c|c|c|c|c|c|}
\hline Group & No & Recipient Vessels & $\begin{array}{c}\text { Breast } \\
\text { Reconstruction }\end{array}$ & Skin graft & $\begin{array}{c}\text { Delayed procedures } \\
\text { (skin paddle removal) }\end{array}$ \\
\hline $\begin{array}{r}\text { Proximal placement } \\
\text { (Axilla) }\end{array}$ & 7 & $\begin{array}{c}\text { Thoraco-Dorsal } \\
\text { system }\end{array}$ & DIEP flap & No & $\begin{array}{c}1 \text { partial DIEP flap loss } \\
1 \text { Seroma at donor site }\end{array}$ & No \\
\hline Distal placement & $\begin{array}{c}\text { Wrist: } 5 \\
\text { Elbow:3 }\end{array}$ & Radial vessels & No & 3 cases & 3 \\
\hline
\end{tabular}

Table 2: Operative details and complications of proximal and distal placement subgroups within group B patients.

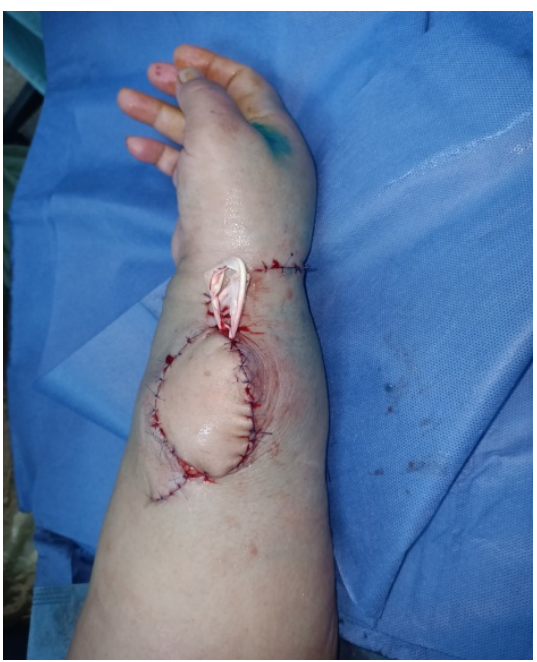

Fig. 6: VGLN transfer at the distal forearm region

All node and DIEP flaps survived (Figure 7) with only 1 case (patient n.7) developed partial DIEP flap loss (about a quarter of the flap) that treated conservatively for 2 weeks then surgical debridement and suturing was performed. Regarding the donor site, there was one case (patient n.5) that developed seroma with $>200 \mathrm{ml}$ fluid within the drain daily for over per week. We managed it successfully with conservative treatment by keeping the drain in situ and compressive dressing for 2 weeks till the drain had minimal fluid (less than 30ml) then removed.

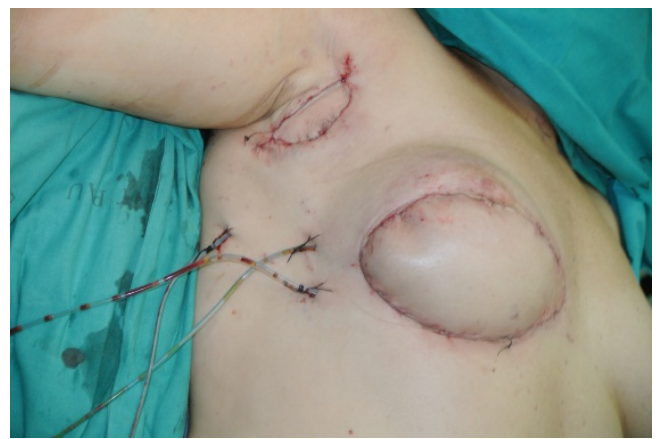

Fig. 7: Combined DIEP and VGLN flap insetting at the chest wall and axilla. 
No donor site lymphedema was observed in all cases of group B.

At a mean follow-up of $30.07 \pm 2.6$ months, the mean improvement of circumferential differentiation of the group B (VGLNT) was statistically greater than that of type A (CDT) $(8.3 \pm 2.7$ compared to $2.1 \pm 4.6$; P $<0.01$ ) (Table 3 )

\begin{tabular}{|c|c|c|c|c|c|c|c|c|}
\hline & \multicolumn{3}{|c|}{$\begin{array}{c}\text { Improvement of Circumferential } \\
\text { Differentiation (\%) }\end{array}$} & \multicolumn{3}{|c|}{ Circumferential Reduction Rate (\%) } & \multirow[b]{2}{*}{$\begin{array}{l}\text { Follow- } \\
\text { up } \\
\text { (months) }\end{array}$} \\
\hline Group & Number & $\begin{array}{l}10 \mathrm{~cm} \text { above } \\
\text { elbow }\end{array}$ & $\begin{array}{l}10 \mathrm{~cm} \text { below } \\
\text { elbow }\end{array}$ & Mean & $\begin{array}{l}10 \mathrm{~cm} \text { above } \\
\text { elbow }\end{array}$ & $\begin{array}{l}10 \mathrm{~cm} \text { below } \\
\text { elbow }\end{array}$ & Mean & \\
\hline VGLNT & 15 & $9.6 \pm 3.8$ & $7 \pm 4$ & $8.3 \pm 2.7$ & $44.4 \pm 13.8$ & $33.2 \pm 28.7$ & $38.8 \pm 16.1$ & $30.07 \pm 2.6$ \\
\hline CDT & 15 & $2.4 \pm 5.3$ & $1.8 \pm 8.3$ & $2.1 \pm 4.6$ & $19.2 \pm 35.4$ & $2.6 \pm 34.5$ & $10.9 \pm 34.7$ & $34.4 \pm 3.8$ \\
\hline Mean \pm SD & & $6 \pm 4.3$ & $4.4 \pm 7.2$ & $4.7 \pm 4.6$ & $31.8 \pm 29.4$ & $17.9 \pm 46.6$ & $24.85 \pm 31.1$ & $32.23 \pm 3.2$ \\
\hline$P$ value & & $<0.01^{*}$ & $<0.01^{*}$ & $<0.01^{*}$ & $0.04 *$ & 0.06 & $0.03 *$ & 0.7 \\
\hline
\end{tabular}

Table 3: Comparisons of the outcomes between patients who underwent VGLNT Flap and those who underwent physical therapy (CDT) instead.

*Analysis of differences between VGLN and CDT groups was performed by means of the Mann-Whitney U test.

Comparing the lymph node recipient sites (Proximal Vs Distal), there have been no statistical differences in mean improvement of circumferential differentiation $(10.1 \pm 4 \%$ versus $6.5 \pm 2.95 \%)$ or circumferential reduction rate (49.15 \pm 17.4 percent versus $28.75 \pm 9.4$ percent) between both subgroups.
The circumferential reduction rate of the belowelbow measurement within the distal group was significantly greater than that within the proximal group $(49.1 \pm 21.7 \%$ versus $17.3 \pm 8.6 \%$; $\mathrm{p}=0.02)$ (Table 4).

\begin{tabular}{|c|c|c|c|c|c|c|c|}
\hline & \multicolumn{3}{|c|}{$\begin{array}{c}\text { Improvement of Circumferential } \\
\text { Differentiation (\%) }\end{array}$} & \multicolumn{3}{|c|}{ Circumferential Reduction Rate (\%) } \\
\hline Group & Number & $\begin{array}{l}10 \mathrm{~cm} \text { above } \\
\text { elbow }\end{array}$ & $\begin{array}{l}10 \mathrm{~cm} \text { below } \\
\text { elbow }\end{array}$ & Mean & $\begin{array}{l}10 \mathrm{~cm} \text { above } \\
\text { elbow }\end{array}$ & $\begin{array}{l}10 \mathrm{~cm} \text { below } \\
\text { elbow }\end{array}$ & Mean \\
\hline Proximal (Axilla) & 7 & $10.7 \pm 3.6$ & $9.5 \pm 3.9$ & $10.1 \pm 4$ & $49.2 \pm 13.1$ & $49.1 \pm 21.7$ & $49.15 \pm 17.4$ \\
\hline Distal (Elbow/wrist) & 8 & $8.5 \pm 4.7$ & $4.5 \pm 1.2$ & $6.5 \pm 2.95$ & $40.2 \pm 10.2$ & $17.3 \pm 8.6$ & $28.75 \pm 9.4$ \\
\hline \multicolumn{2}{|l|}{ Mean \pm SD } & $9.6 \pm 3.8$ & $7 \pm 4$ & $8.3 \pm 3.9$ & $44.6 \pm 13.8$ & $33.2 \pm 28.7$ & $38.9 \pm 21.25$ \\
\hline \multicolumn{2}{|l|}{$P$ value } & 0.6 & $0.01 *$ & 0.12 & 0.3 & $0.02 *$ & 0.06 \\
\hline
\end{tabular}

Table 4: Comparisons of the Outcomes between Patients Who Underwent VGLNT Using Proximal Recipient Site (Axilla) and distal Instead (Elbow/wrist).

*Analysis of differences between Wrist and Elbow groups was performed by means of the Mann-Whitney U test.

Regarding the cellulitis attacks, each treatment showed a major reduction of the number of attacks in $\mathrm{B}(\mathrm{p}=0.06$ in $\mathrm{A}$ and $\mathrm{p}<0.001 *$ in group $\mathrm{B})$.

Regarding the subjective symptoms including pain, heaviness, and functional improvement, the conservative treatment alone was clearly inferior compared to the surgical treatment applied to group B patients ( $\mathrm{p}<$ or $=0.000$ for all, Table 5).

\begin{tabular}{|c|c|c|c|c|}
\hline & $\begin{array}{c}\text { Group } \\
\text { A }\end{array}$ & $P$ value & $\begin{array}{c}\text { Group } \\
\text { B }\end{array}$ & $P$ value \\
\hline $\begin{array}{l}\text { Mean I Pre } \\
\text { Mean I post }\end{array}$ & $\begin{array}{l}2.3 \\
1.0 \\
\end{array}$ & 0.06 & $\begin{array}{c}2.46 \\
0.0 \\
\end{array}$ & $<0.001^{*}$ \\
\hline $\begin{array}{l}\text { Mean P pre } \\
\text { Mean P post } \\
\end{array}$ & $\begin{array}{c}4.8 \\
3.73 \\
\end{array}$ & 0.1 & $\begin{array}{c}5.2 \\
0.73 \\
\end{array}$ & $0.000^{*}$ \\
\hline $\begin{array}{l}\text { Mean } \mathrm{H} \text { pre } \\
\text { Mean } \mathrm{H} \text { post }\end{array}$ & $\begin{array}{c}6.8 \\
5.93 \\
\end{array}$ & 0.4 & $\begin{array}{c}6.2 \\
0.93 \\
\end{array}$ & $0.000^{*}$ \\
\hline $\begin{array}{l}\text { Mean F pre } \\
\text { Mean F post }\end{array}$ & $\begin{array}{c}6.2 \\
4.93 \\
\end{array}$ & 0.08 & $\begin{array}{l}6.73 \\
1.06 \\
\end{array}$ & $<0.001^{*}$ \\
\hline
\end{tabular}

Table 5: Correlation of mean pain, heaviness, infection rate and overall function of the affected upper extremity in both groups A and B before and 12 months after the completion of any treatment. (I infection, $\mathrm{P}$ pain, $\mathrm{H}$ heaviness, $\mathrm{F}$ function)

Paired t test and Wilcoxon Signed-Rank test were used, Statistical significance was accepted at $\mathrm{p}$ values less than 0.05. * means significant.

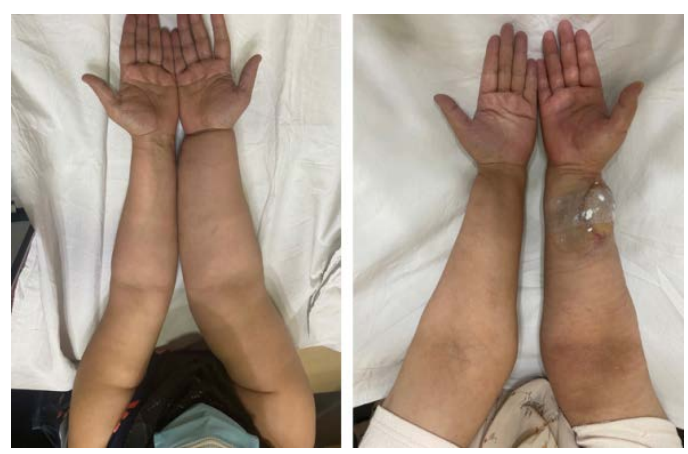

Fig. 8: Preoperative (Left) and postoperative (Right) photos of female patient 60 years old suffering from BCRL and underwent VGLNT with flap placement at the wrist region.

\section{DISCUSSION}

The pathophysiology of breast cancer-related lymphoedema (BCRL) results from disruption of lymphatic channels with/out radiotherapy, which ends up in interruption of lymphatic drainage, accumulation of protein-rich fluid with overall increased interstitial pressure. ${ }^{11,12}$ This increased pressure initiates an inflammatory cascade with recurrent cellulitis resulting in increased edema and more obstruction. 
Recently, microsurgical LVA and lymph node transfer had been proved as safe and reliable approaches for the management of BCRL. ${ }^{13,14}$ However, the literature lacks head-to-head prospective comparative clinical studies between microsurgical lymph node transplantation and CDT management. In our prospective, we aimed to match the outcomes and effectiveness of both interventions (VLNT and CDT) in a selected cohort of patients with BCRL.

Following an analogous CDT protocol by lymphoedema specialized physiotherapists, our results showed that at 1-year follow-up, the patients of group $\mathrm{B}$ who underwent the VGLNT had a significantly lower recurrence rate of edema, as compared to people who were managed by CDT alone (group A); as most of the group A patients returned to their previous lymphoedema situation once they discontinued the CDT. Although many studies reported the effectiveness of CDT in minimizing the lymphedema symptoms and comparatively improved

the quality of life especially in dedicated patients, it demands strict adherence to compression garments, short stretch bandage for her life which make most patients non-compliant to such intensive physical management. ${ }^{15-18}$

Lymphedema-related infection reports have shown the role of lymphoedema limb volume reduction in decreasing the incidence rate of cellulitis or lymphangitis. ${ }^{19,20}$ However, patients with BCRL are still in danger of lymphoedema progression and recurrent cellulitis whether or not they strictly adhered to CDT management protocol.

Several proposed mechanisms of how the vascularized node flap transfer could improve lymphedema include the lymph node flap act as "lymph pumps," where the pressure gradient between the high-pressure arterial inflow and therefore the low-pressure venous outflow directs the fluid from the interstitial space to the undamaged lymph nodes and into the venous system through the natural lymphatico-venous shunts within the nodes of the transferred flap. ${ }^{19,20}$ Another important mechanism that was proven experimentally, the lymph node transfer increases endogenous expression of vascular endothelial growth factor- C (VEGF-C), improve lymphangiogenesis. ${ }^{21-23}$

The "Sponge effect" may recruit more lymph fluid from the surrounding interstitial tissue of the affected limb into the transferred lymph nodes. ${ }^{23}$ Granzow et al. reported a significant reduction in the need for both compression garment use and physiotherapy, a decreased overall episode of lymphangitis, and a significant limb volume reduction postoperatively compared with the preoperative limb volume condition $(p<0.0001) .{ }^{24}$ Similarly, our study had demonstrated a significant reduction of cellulitis attacks in patients who underwent VLNT, compared to the CDT group of patients $(\mathrm{p}<0.001)$.

Regarding the morbidity of the donor site, Becker et al. reported that the superficial inguinal lymph nodes located around the superficial circumflex iliac vessels and above the inguinal crease principally drain lymph from the lower abdominal wall and care should be taken to avoid harvesting the lower extremity sentinel lymph nodes, which are located more inferior and deep near the common femoral vessels. ${ }^{25,26}$ However, donor site lymphedema was reported. ${ }^{27,28}$ We performed reverse lymphatic mapping in every case of VGLNT included in our study using either fluorescence or isotope mapping and no lower limb lymphedema was reported at mean follow-up $30.07 \pm 2.6$ month.

For the VGLNT group, there are three recipient sites available for lymph tissue transfer with a lot of controversy in the literature. ${ }^{29}$ Despite the axillary area is typically operated previously and irradiated, which makes the dissection of recipient's vessels harder, the release of the scary fibrotic tissue and decompression of the axillary veins could improve the lymphatic obstruction so, we used usually when lymphedema treatment was combined with breast reconstruction using DIEP flap. Distal lymph node flap placement has the benefits of intact healthy recipient vessels and improving distal limb lymph drainage against gravity. ${ }^{30,31}$ In our study, we used the axilla in cases of amastia to facilitate our approach using combined chimeric DIEP and lymph node flap. The sole difference between the proximal and distal LN flap placement was the gravity effect. In our opinion, for patients with stage III lymphedema with long-term manifestations, the distal placement is the preferred recipient site for a better outcome.

None of the patients with VGLNT required CDT longer than 6 months after surgery, with obviously improved quality of life.

Although the groin region is that the most wellliked donor site for VLNT thanks to its reliability, adequate number of LNs, relatively constant vascular pedicle, concealed scar, and also the possibility to be combined with DIEP flap in cases of desired breast reconstruction and BCRL treatment, other donor sites were described because of the inherent risk of donor-site lymphedema. Various donor lymphatic node flaps had been described in the literature, like the submental flap, supraclavicular flap, lateral thoracic, and omental flaps. However, each donor site for lymph node flap has its benefits and drawbacks. ${ }^{32}$

\section{CONCLUSION}

Vascularized groin lymph node transfer with reverse lymphatic mapping, using the wrist, elbow or axilla as a recipient site could be a reliable and safe approach to treat secondary upper limb lymphedema.

\section{REFERENCES}

1. Rockson SG. Lymphatics: where the circulation meets the immune system. Lymphat Res Biol 2013;11(3):115.

2. Rockson SG. Physiology, Pathophysiology, and Lymphodynamics: General Overview. In: Lee B, Bergan J, Rockson S, editors. Lymphedema: A Concise Compendium of Theory and Practice. London: Springer; 2011. p. 59-61. 
3. Srinivasan RS, Dillard ME, Lagutin OV, et al. Lineage tracing demonstrates the venous origin of the mammalian lymphatic vasculature. Genes \& development. 2007 1; 21(19): 242232.

4. Oliver G. Lymphatic vasculature development. Nat Rev Immunol 4:35-45, 2004.

5. Rockson SG, Miller LT, Senie R, et al. Workgroup III: Diagnosis and management of lymphedema. Cancer: Interdisciplinary International Journal of the American Cancer Society. 1998 15;83(S12B):2882-5.

6. Moseley AL, Piller NB and Carati CJ. The effect of gentle arm exercise and deep breathing on secondary arm lymphedema. Lymphology 2005;38(3):136-45.

7. Basta MN, Gao LL and Wu LC. Operative treatment of peripheral lymphedema: A systematic meta-analysis of the efficacy and safety of lymphovenous microsurgery and tissue transplant. Plast Reconstr Surg. 2014; 133: 905-13.

8. Campisi C and Boccardo F. Microsurgical techniques for lymphedema treatment: Derivative lymphatic-venous microsurgery. World J Surg. 2004; 28:609-613.

9. Hanson SE, Chang EI, Schaverien MV, et al. Controversies in surgical management of lymphedema. Plastic and Reconstructive Surgery Global Open. 2020;8(3).

10. Pons G, Abdelfattah U, Sarria J, et al. Reverse Lymph Node Mapping Using Indocyanine Green Lymphography: A Step Forward in Minimizing Donor-Site Morbidity in Vascularized Lymph Node Transfer. Plastic and Reconstructive Surgery. 2021 1;147(2):207e-12e.

11. Haagensen CD, Feind CR, Herter FP, et al. The lymphatics in cancer. WB Saunders; 1972.

12. Greenlee R, Hoyme $\mathrm{H}$, Witte $\mathrm{MH}$, et al. Developmental disorder of the lymphatic system. Lymphology. 1993 9; 26(4): 156-68.

13. Földi E, Földi $M$ and Clodius L. The lymphedema chaos: a lancet. Annals of plastic surgery. 1989 1; 22(6):505

14. Becker C, Pham DN, Assouad J, et al. Postmastectomy neuropathic pain: results of microsurgical lymph nodes transplantation. The Breast. 2008 1;17(5):472-6.

15. Szuba A, Cooke JP, Yousuf S, et al. Decongestive lymphatic therapy for patients with cancer-related or primary lymphedema. The American journal of medicine. 2000 1; 109(4): 296-300.
16. Damstra RJ, Voesten HG, Van Schelven WD, et al. Lymphatic venous anastomosis (LVA) for treatment of secondary arm lymphedema. A prospective study of 11 LVA procedures in 10 patients with breast cancer related lymphedema and a critical review of the literature. Breast cancer research and treatment. 2009; 113(2): 199-206.

17. Boris $\mathrm{M}$, Weindorf S, Lasinski $\mathrm{B}$, et al. Lymphedema reduction by noninvasive complex lymphedema therapy. Oncology (Williston Park, NY). 1994 1; 8(9):95-106.

18. SITZIA J. Volume measurement in lymphoedema treatment: examination of formulae. European journal of cancer care. 1995; 4(1):11-6.

19. Mallon E, Powell S, Mortimer P, et al. Evidence for altered cell-mediated immunity in postmastectomy lymphoedema. British Journal of Dermatology. 1997;137(6): 928-33.

20. Földi E. Prevention of dermatolymphangioadenitis by combined physiotherapy of the swollen arm after treatment for breast cancer. Lymphology. 1996; 29(2): 48-9.

21. Cheng $\mathrm{MH}$, Huang JJ, Wu CW, et al. The mechanism of vascularized lymph node transfer for lymphedema: natural lymphaticovenous drainage. Plastic and reconstructive surgery. 2014 1;133(2):192e-8e.

22. Aschen SZ, Farias-Eisner G, Cuzzone DA, et al. Lymph node transplantation results in spontaneous lymphatic reconnection and restoration of lymphatic flow. Plastic and reconstructive surgery. 2014;133(2):301.

23. Chang EI, Ibrahim A, Liu J, et al. Optimizing Quality of Life for Patients with Breast Cancer-Related Lymphedema: A Prospective Study Combining DIEP Flap Breast Reconstruction and Lymphedema Surgery. Plastic and reconstructive surgery. 2020 1; 145(4): 676e-85e.

24. Granzow JW, Soderberg JM, Kaji AH, et al. An effective system of surgical treatment of lymphedema. Annals of surgical oncology. 2014; 21(4):1189-94.

25. Becker C, Hidden G, Godart S, et al. Free lymphatic transplant. Eur J Lymphol Rel Prob. 1991; 6:25-77.

26. Azuma, S., Yamamoto, T. and Koshima, I. Donor-site lymphatic function after microvascular lymph node transfer should be followed using indocyanine green lymphography. Plastic and reconstructive surgery 2013; 131:443e-444e. 
27. Vignes S., Blanchard M., Yannoutsos A., et al. Complications of autologous lymph-node transplantation for limb lymphoedema. European Journal of Vascular and Endovascular Surgery 2013; 45:516-20.

28. Pons, G., Masia, J., Loschi, P., et al. A case of donor-site lymphoedema after lymph nodesuperficial circumflex iliac artery perforator flap transfer. Journal of Plastic, Reconstructive \& Aesthetic Surgery 2014; 67:119-23.

29. Aljaaly HA, Fries CA and Cheng MH. Dorsal Wrist Placement for Vascularized Submental Lymph Node Transfer Significantly Improves Breast Cancer-Related Lymphedema. Plastic and Reconstructive Surgery Global Open. 2019; 7(2).
30. Patel KM, Lin CY and Cheng MH. A prospective evaluation of lymphedema-specific quality-of-life outcomes following vascularized lymph node transfer. Annals of surgical oncology. 2015;22(7):2424-30.

31. Cheng MH, Chen SC, Henry SL, et al. Vascularized groin lymph node flap transfer for postmastectomy upper limb lymphedema: flap anatomy, recipient sites, and outcomes. Plastic and reconstructive surgery. 2013 1;131(6):1286-98.

32. Pappalardo $\mathrm{M}$, Patel $\mathrm{K}$ and Cheng $\mathrm{MH}$. Vascularized lymph node transfer for treatment of extremity lymphedema: an overview of current controversies regarding donor sites, recipient sites and outcomes. i2018;117(7):1420-31. 